\title{
Relationship Between Dietary Fatty Acids and Reproductive Functions in Dairy Cattle
}

\author{
Ercan Soydan', Uğur Şen ${ }^{*}$, Emre Şirin ${ }^{2}$ \\ ${ }^{1}$ Department of Agricultural Biotechnology, Faculty of Agriculture, Ondokuz Mayis University, 55139 Samsun, Turkey \\ ${ }^{2}$ Department of Agricultural Biotechnology, Faculty of Agriculture, Ahi Evran University, 40100 Așıkpaşa/Kirsehir, Turkey \\ A R T I C L E I N F O

\section{Review Article} \\ Received 11 April 2017 \\ Accepted 06 July 2017 \\ Keywords: \\ Fatty acids \\ Hormones \\ Reproductive performance \\ Fertility \\ Dairy cattle \\ *Corresponding Author: \\ E-mail: ugur.sen@ahievran.edu.tr \\ A B S T R A C T \\ Selection of dairy cattle for higher milk yield, without considering important non- \\ production traits, has decreased reproductive efficiency. Thus, low reproductive \\ performance is a major problem in high yielding dairy cattle. Previous studies showed \\ that dietary manipulation to improve fertility holds much promise and dietary fats have \\ positive effects on reproductive functions in high yielding dairy cattle. Positive effects of \\ fats on reproductive performance due to the fatty acids, which are the precursors of \\ progesterone and prostaglandins. Progesterone and prostaglandins hormones are most \\ important factors that play a role on the control of reproductive functions. The amount of \\ linoleic, linolenic and arachidonic fattty acids in ration can be increase or decrease \\ progesterone and prostaglandins synthesis especially $\mathrm{PGF}_{2 \alpha}$ from ovary and uterus, \\ respectively. Also fatty acids can be influence follicular development, ovulation, \\ embryonic implantation and maternal recognition of pregnancy. This review focuses on \\ the relationships between dietary fatty acids and reproductive functions such as hormone \\ profiles, ovarian function and follicular development, oocyte quality, embryo \\ development, embryonic implantation and maternal recognition of pregnancy in dairy \\ cattle.
}

DOI: https://doi.org/10.24925/turjaf.v5i12.1575-1579.1271

\section{Introduction}

It has been emphasized that genetic selection of dairy cows primarily for higher milk yield, without considering important non-production traits (fertility, mastitis resistance) will cause a further decline in fertility (Abayasekara and Wathes, 1999; Petit et al., 2002). Fortunately, dietary manipulation to improve fertility holds much promise. Several excellent reviews are available on this topic (Ambrose and Kastelic, 2003; Petit et al., 2002; Thatcher et al., 2004). These reviews reported that dietary fat improvement dairy cow fertility. Although the mechanisms through which dietary fats enhance reproductive performance in dairy cattle are not well understood, several hypotheses have been put forth. These hypotheses propose that supplemental dietary fat improves fertility via: 1) an amelioration of negative energy status, leading to an earlier return to estrus during the postpartum period and, therefore, improved fertility; 2) an increased in steroidogenesis (production of steroid hormones, progesterone) favorable to improved fertility; 3) manipulation of serum insulin concentrations, thereby stimulating development of ovarian follicles; and 4) altering the production and release of series 2 prostaglandin $\left(\mathrm{PGF}_{2 \alpha}\right)$, which causes regression of the corpus luteum.

The positive effects of dietary fat on fertility in dairy cows could be due to effects of certain dietary fatty acids on the pituitary, ovaries and uterus, rather than via improved energy status (Dipak et al., 2013; Rodney et al.,
2015). It is believed that only certain dietary fats can suppress $\mathrm{PGF}_{2 \alpha}$ production because specific fatty acids (polyunsaturated fatty acids; PUFA) are known to play a key role in $\mathrm{PGF}_{2 \alpha}$ syntheses. Therefore, by manipulating the fatty acid profile of diets, uterine syntheses of prostaglandins (PG) during early pregnancy can potentially be suppressed, resulting in a reduction in embryonic mortality. This is an area of research that is beginning to receive attention. In the past few years, several reports have indicated that diets enriched in specific fatty acids (particularly those of the omega-3 family) improve fertility in dairy cows. This review focuses on the relationships between dietary fatty acids and reproductive functions such as hormone profiles, ovarian function and follicular development, oocyte quality, embryo development, embryonic implantation and maternal recognition of pregnancy in dairy cattle.

\section{Fatty Acids}

Fatty acids are classified as either "unsaturated" or "saturated" and saturated fatty acids have no double bonds, whereas unsaturated fatty acids have one (monounsaturated; MUFA) or more (polyunsaturated; PUFA) double bonds in their structure (Petit et al., 2002). Unsaturated fatty acids are also classified into different classes according to the number of carbon atoms (Abayasekara and Wathes, 1999). For example, linoleic 
acid (LA) has 18 carbon atoms and two double bonds and it is conventionally written as C18:2. Depending on the location of the first double bound relative to the methyl end of the fatty acid chain, PUFA are also classified as members of either the Omega-3 (n-3) family (C18:3) or the Omega-6 (n-6) family (C18:2) (Ambrose and Kastelic, 2003; Otto et al., 20014). Animals can synthesize most fatty acids, with the notable exception of fatty acids belonging to the $n-3$ and $n-6$ families. Since animals must have a dietary source of these fatty acids, they are considered essential fatty acids. When consumed by animals, linoleic acids, found mainly in oilseeds, is desaturated (insertion of double bonds) and elongated (addition of carbon atoms) to form arachidonic acid. In contrast, $\alpha$-linolenic acid, found predominantly in forage (grass, legume leaves) and select oilseeds (flaxseed), is desaturated and elongated to form two fatty acids that are unique to fish oil; eicosapentaenoic acid and docosahexaenoic acid (Petit et al., 2002; Ambrose and Kastelic, 2003).

\section{Sources of Fatty Acids}

The main sources of short chain fatty acids are cottonseed and palm oils. All sources of fat contain long chain fatty acids. The main sources of linolenic acid are flaxseed, hemp, canola, soybean, nuts and dark green forages. Ryegrass silage contains as much as $60 \%$ of linolenic acid as a percentage of total fatty acids (Petit et al., 2001; Thatcher et al., 2004), which would encourage high forage systems to increase dietary linolenic acid content. Omega-3 fatty acids are found also in cold water and salt water fish such as salmon, trout, mackerel and sardines. The main sources of linoleic acid are sunflower seed, safflower, hemp, soybean, nuts, pumpkin seeds, sesame seeds and flaxseed. Gamma-linolenic acid is found in evening primose oil, grape seeds and borage (Petit et al., 2002). Dihomogamma-linolenic acid is found in maternal milk while arachidonic acid occurs mainly in meat and animal products. Oleic acid is found in olive, almond, avocado, peanut, pecan, cashew, macadamia nut and butter. Palmitoleic acid, which is omega 7 form, is found in tropical oils such as coconut and palm (Petit et al., 2001; Thatcher et al., 2004).

\section{Fatty Acid and Prostaglandin}

Prostaglandins (PG) play an important role in reestablishing estrous cycles both immediately after parturition and thereafter until conception occurs (Mattos et al., 2000). The synthesis of $\mathrm{PGF}_{2 \alpha}$ from arachidonic acid (omega-6) is regulated by the key enzyme, prostaglandin endoperoxide synthase (PGHS). Linoleic acid (omega-6) is converted to arachidonic acid which is the immediate precursor to prostaglandins. A decrease in arachidonic acid biosynthesis by low conversion of linoleic acid to arachidonic acid would decrease $\mathrm{PGF}_{2 a}$ secretion. Within the reproductive tract of cows, uterine tissue is a primary source of the $\mathrm{F}$ series prostaglandins especially $\mathrm{PGF}_{2 \alpha}$ during the early postpartum period. The major uterine tissue producing $\mathrm{PGF}_{2 \alpha}$ is the caruncular tissue, and the metabolite of $\mathrm{PGF}_{2 \alpha}$ is produced both in the uterus locally and the lung where $\mathrm{PGF}_{2 \alpha}$ is metabolized (Abayasekara and Wathes, 1999; Petit et al., 2002). Thatcher et al. (2004) reported that beef heifers were fed rumen by-pass fat containing linoleic acid for the first 30 days postpartum increased $\mathrm{PGF}_{2 \alpha}$ secretion.

Increased availability of the omega-3 fatty acid especially eicosapentaenoic acid (EPA) may lead to suppression in the synthesis of $\mathrm{PGF}_{2 \alpha}$ by the uterus by competing for PGHS. Dihomo- $\gamma$-linolenic acid (omega-6) can compete for PGHS when it is converted to the series one prostaglandins. Although docosahexaenoic acid (omega-3; DHA) is not a substrate for PGHS, it is a strong inhibitor of PGHS activity. Also intake of $\alpha$ linolenic (omega-3; ALA) or eicosapentaenoic (omega-3; EPA) acids decrease conversion of arachidonic acid to $\mathrm{PGF}_{2 \alpha}$. The increased presence of EPA and DHA can inhibit the synthesis of arachidonic acid from linoleic acid by inhibiting the desaturation and elongation enzymes required for that conversion (Mattos et al., 2000). ALA also can compete with linoleic acid for the desaturase enzymes so that more EPA and less arachidonic acid are synthesized. In addition, the omega- 3 fatty acids can displace arachidonic acid in the phospholipids of cell membranes thus reducing availability of arachidonic acid. Therefore increasing the dietary intake of the omega-3 fatty acids can reduce the production of $\mathrm{PGF}_{2 \alpha}$ (Mattos et al., 2000; Otto et al., 20014).

Dietary omega-3 can decrease $\mathrm{PGF}_{2 \alpha}$.synthesis by different actions, which include decreasing the availability of precursor arachidonic acid, increasing the concentration of fatty acids that compete with arachidonic acid for series 2 PG, and inhibiting PG synthase. Reduced availability of arachidonic acid in the uterine phospholipid membranes for conversion to series 2 PG can occur through a reduction in the synthesis of arachidonic acid or through displacement of existent arachidonic acid from the phospholipid membranes by other fatty acids. In summary, inhibition of PG secretion can be achieved through: 1) reduced synthesis of arachidonic acid by desaturase enzymes necessary for conversion of linoleic acid to arachidonic acid; 2) alteration in fatty acid profile in favor of omega-3 in membrane phospholipids which may or may not be precursors of other eicosanoids; 3 ) inhibition of synthesis and activity of cyclooxygenase enzymes responsible for the synthesis of $\mathrm{PGF}_{2 \alpha}$; 4) inhibition of gene expression involved in the synthesis of series 2 PG (Mattos et al., 2000: Otto et al., 20014).

The potential relevance of the ability of omega-3 fatty acid like EPA to inhibit secretion of $\mathrm{PGF}_{2 \alpha}$ is its ability to regulate secretion of $\mathrm{PGF}_{2 \alpha}$ in combination with the antiluteolytic protein Interferon- $\tau$. Interferon- $\tau$ will inhibit the phorbol ester induction of $\mathrm{PGF}_{2 \alpha}$ secretion by bovine endometrial cells (Thatcher et al., 2004). However, when the cells are incubated with EPA for a $24 \mathrm{~h}$ period, the subsequent phorbol ester induction of $\mathrm{PGF}_{2 \alpha}$ secretion is suppressed in an additive manner with Interferon- $\tau$. The implication of this finding is that supplementation with inhibitory fatty acids such as EPA during early pregnancy by dietary or parenteral means may further enhance the suppression of $\mathrm{PGF}_{2 \alpha}$ secretion in concert with the action of embryonic bIFN- $\tau$. Because a significant proportion of bovine embryos is thought to be lost due to inadequate inhibition of uterine $\mathrm{PGF}_{2 \alpha}$ secretion, further inhibition by exogenous means may result in increased embryo survival (Thatcher et al., 2004). 


\section{Fatty Acids and Progesterone}

Cholesterol serves as a precursor for the synthesis of progesterone by ovarian luteal cells. Much of the early embryonic loss occurring in mammals is due to inadequate function of luteal cells (Abayasekara and Wathes, 1999; Petit et al., 2002). The main function of the luteal cells in the corpus luteum (CL) is to synthesize progesterone. Progesterone helps prepare the uterus for implantation of the embryo and also helps maintain pregnancy by providing nourishment to the conceptus. Increased concentrations of plasma progesterone have been associated with improved conception rates of lactating ruminants.

Kuran et al (1999), showed that diet supplementation of palm oil protected with calcium soaps increased progesterone concentration in follicular fluid in sheep in vitro. Dairy cows fed supplemental fat (tallow, CaLCFA or prilled fatty acids) often have small increases in blood progesterone concentration (Thatcher et al., 2004). Hawkins et al. (1995) suggests that increases in plasma progesterone in cows fed fat-supplemented diets may not be due to increased synthesis but rather reduced clearance of progesterone from circulation. On days 12 to 13 of the third cycle, heifers were ovariectomized. Repeated blood samples taken immediately before and after ovariectomy indicated that the half-life of serum progesterone was increased in heifers fed fat. Authors suggested that prolonged elevated concentrations of progesterone were due to a reduced rate of clearance from the blood rather than an increased rate of secretion.

The fatty acid profile of the dietary fat may influence the propensity of animals to increase plasma progesterone (Dipak et al., 2013; Rodney et al., 2015). Mature ewes were infused intravenously with saline, soybean oil, or olive oil for 5 h on d 9 through 13 of an estrous cycle (Burke et al., 1997). Serum cholesterol was increased by fat infusate and olive oil was more effective than soybean oil $(127,141$, and $153 \mathrm{mg} / \mathrm{dl}$ for saline, soybean oil, and olive oil, respectively). However, soybean oil infusion resulted in greater progesterone response than did infusion of olive oil at $2.5 \mathrm{~h}$ post infusion. Therefore, the greatest concentration of serum cholesterol did not coincide with the greatest concentration of serum progesterone.

\section{Reproductive Effects of Fatty Acids}

Deficiency of essential fatty acids in experimental animals can cause various disorders associated with defective cell membranes, including impaired growth, skin and connective tissue abnormalities, and impaired fertility (Ambrose and Kastelic, 2003). In some animals, PUFA may play an important role in many reproductive processes including ovulation, fertilization and parturition (Abayasekara and Wathes, 1999). In cattle, dietary fatty acids can influence ovarian follicular growth, CL function and progesterone production (Abayasekara and Wathes, 1999; Mattos et al., 2000). Prepartum diets high in PUFA of the n-3 family delayed parturition in sheep (Ambrose and Kastelic, 2003) and increased the incidence of placental retention in cattle (Barnouin and Chassagne, 1991). In contrast, increasing the dietary availability of n3 PUFA during the postpartum period improved pregnancy rates in cattle (Petit et al., 2001; Ambrose and Kastelic, 2003) likely through a decrease in uterine PG secretion during early pregnancy (Thatcher et al., 1997). There is a specific need to develop different feeding strategies according to the reproductive stage of cows; fatty acids required for better maternal recognition (omega 3) won't be necessarily the same as those required for easier calving (omega 6). The only problem is that polyunsaturated fatty acids (omega 3 and omega 6) are biohydrogenated by rumen microbes and these fatty acids must bypass the rumen to have any effect on reproduction. These fatty acids must therefore be protected against the attack of rumen microbes but they must remain digestible in the intestine and this is even more important for free oils. Oils contained in fish meal (EPA and DHA) escape partially biohydrogenation in the rumen (Ashes et al., 1992; Petit et al, 2002)

Undesirable conditions prior to ovulation, such as negative energy balance, may have carry over effects on embryo metabolism and viability resulting in unsuccessful early embryonic survival. Therefore, manipulating of negative energy balance by the fatty acid profile of diets may improve embryo quality and may reduce early embryonic mortality or loss. Previous studies reported that supplementation with unsaturated FA (transoctadenoic and linoleic acids) have been shown to improve embryo quality and development, leading to overall higher pregnancy rates and reduced pregnancy losses (Cerri et al., 2009; Juchem et al., 2010).

It is clear that the PUFA are important for reproduction. The practical significance to the dairy farmer is the potential ability to reduce embryonic loss by feeding PUFA enriched diets to reduce/suppress PG secretion in dairy cattle during the critical period of maternal recognition of pregnancy.

\section{Follicular Development}

A variety of fat sources have influenced the size and number of ovarian follicles. Several studies have shown that feeding supplemental fat alters the growth dynamics of the ovarian follicle and that this effect is somewhat independent from energy. Supplemental fat feeding in a manner that was isocalorific with the control diet without fat supplement stimulated programmed growth of a preovulatory follicle (Mattos et al., 2000). Effects of supplemental fat also include increased total number of follicles (Beam and Butler, 1997; Lammoglia et al., 1997) and increased size of preovulatory follicles (Beam and Butler, 1997; Mattos et al., 2000). An increase in the number of smaller follicles may reflect a greater pool of follicles available for subsequent development. A greater number of larger follicles may indicate an altered selection process. In addition to the increased numbers of follicles due to fat supplementation, the size of the dominant follicle has commonly been increased (Thatcher et al., 1996; Thatcher et al., 2004). Larger follicles usually occur under conditions of low concentrations of progesterone and high estradiol 17-b.This hormonal profile is just the opposite of what is seen typically when fat is supplemented. The impact of larger ovarian follicles due to the feeding of supplemental fat on conception rate has not been defined. If a follicle becomes too large $(>25$ $\mathrm{mm}$ ), it can become cystic and fail to ovulate (Thatcher et al., 2004). The size of a healthy follicle may have no relationship to the amount of estradiol it secretes or to the secretion of progesterone by the subsequent CL formed. The mechanism by which dietary fats stimulate ovarian 
activity has yet to be determined (Thatcher et al., 1996). Two mechanisms of action have been suggested. The first is via increased blood cholesterol (both total and high density lipoprotein-cholesterol. As cholesterol is the precursor of all steroids, increased substrate availability may increase follicular steroid synthesis. The following findings support this contention: (1) androstenedione levels were found to be increased in follicular fluid of cows fed a high lipid diet and (2) granulosa cells obtained from follicles of cows fed a high-lipid diet increased progesterone output in vitro. Oestradiol-17b produced by the coordinate actions of the steroidogenic enzymes in theca and granulosa cells, induces granulosa cell proliferation. This in turn would ultimately result in an increase in follicular size (Abayasekara and Wathes, 1999).

A second alternative, yet complementary, explanation could be that increased dietary fats led to an increase in AA in phospholipids of ovarian follicular granulosa cells. When released from phospholipids in response to gonadotrophin stimulation, the AA could either have a direct effect on granulosa cells steroidogenesis or be metabolized via the cyclooxygenase pathway to yield prostaglandins (Abayasekara and Wathes, 1999; Mattos et al., 2000). These in turn may exert a stimulatory effect on granulosa cell steroidogenesis. The latter suggestion is supported by the observations that gonadotrophins stimulate prostaglandin production in ovarian follicular cells and prostaglandins $\left(\mathrm{PGE}_{2}\right)$ in turn, are known to stimulate ovarian steroidogenesis (Mattos et al., 2000). Additionally increased size of preovulatory follicles may be due in part to increased concentrations of plasma $\mathrm{LH}$, which stimulates the latter stage of follicular growth. Further research is required to determine whether dietary fatty acids affect the secretion of LH and whether increased size and numbers of follicles are associated with increased pregnancy rates (Mattos et al., 2000).

\section{Maternal Recognition of Pregnancy}

Arachidonic acid is the rate limiting fatty acid for the synthesis of $\mathrm{PGF}_{2 \alpha}$ via the action of $\mathrm{PGF}_{2 \alpha}$ synthase (Abayasekara and Wathes, 1999; Mattos et al., 2000; Ambrose and Kastelic, 2003). The same enzymes also are capable of processing other fatty acids, such as EPA, which is the precursor for the synthesis of prostanoids of the 3 series. Increased availability of EPA in membrane phospholipids could displace arachidonic acid, leading to increased synthesis of prostanoids of the 3 series at the expense of prostanoids of the 2 series, such as $\mathrm{PGF}_{2 \alpha}$. Prostanoids of the 3 series are less bioactive, and there appears to be no evidence for their role in ruminant luteolysis. Gamma-linolenic acid and EPA have been shown to reduce the synthesis in vitro of $\mathrm{PGF}_{2 \alpha}$ and PGE2 (Petit et al., 2001; Petit et al., 2002).

Interferon- $\tau$, but not EPA, reduced levels of enzyme gene expression (cyclooxygenase-2) and thus modulates $\mathrm{PGF}_{2 \alpha}$ production (Mattos et al., 2000; Thatcher et al., 2004; Petit et al, 2002). On the other hand, EPA does not seem to affect enzyme gene expression but would be involved in competition of precursors for processing by the cyclooxygenase enzymes, and regulation of enzyme activity. The implication of these findings is that supplementation with inhibitory fatty acids such as EPA during early pregnancy by dietary or parenteral means may further enhance the suppression of $\mathrm{PGF}_{2 \alpha}$ secretion in concert with the action of embryonic Interferon- $\tau$ Mattos et al., 2000; Petit et al, 2002). Because a significant proportion of bovine embryos are thought to be lost due to inadequate inhibition of uterine $\mathrm{PGF}_{2 \alpha}$ secretion, further inhibition by exogenous means may result in increased embryo survival. This hypothesis is supported by the findings of Burke et al. (1997), in which feeding lactating dairy cows of low fertility a source of EPA and DHA in fish meal increased pregnancy rates.

\section{Corpus Luteum Function}

Follicular rupture leads to the formation of CL. Fat composition of the diet has been suggested to influence luteal function in three different ways: by a direct action on progesterone production; via alteration of the production of eicosanoids within luteal tissue and/or by interaction with the system controlling luteolysis and the maternal recognition of pregnancy (Abayasekara and Wathes, 1999).

Lipid infusion to either cattle or sheep during the luteal phase increases serum concentrations of progesterone (Burke et al., 1997; Abayasekara and Wathes, 1999). This may have been due to raised cholesterol levels providing an increase in available precursor for progesterone biosynthesis. Another possibility is that clearance rates of progesterone from plasma may be reduced (Abayasekara and Wathes, 1999; Thatcher et al., 2004). Both soybean oil and olive oil increased circulating progesterone concentrations, although soybean oil was more effective (Burke et al., 1997). This elevation in progesterone could have a beneficial effect on fertility, as sub-optimal progesterone concentrations are associated with high return rates in cows

The increase in luteal $\mathrm{PGF}_{2 \alpha}$ at the time of luteal regression in rats may be due, in part, to an increase in arachidonic acid, and hence its metabolites including $\mathrm{PGF}_{2 \alpha}$, which are then available to exert an inhibitory action on progesterone production. The finding that the bovine CL contains very high levels of PUFAs, especially arachidonic acid, esterified in phospholipids (Petit et al, 2002) supports this notion. Furthermore the level of arachidonic acid is highest in the mid- and late-luteal phase of corpora luteal of domestic ruminants (sheep and cow). Luteal cells from cows fed a diet high in n-3 PUFA produce significantly greater quantities of progesterone under basal conditions. This suggests that products of $n-3$ PUFA oxygenation, namely the trienoic prostaglandins, are capable of stimulating progesterone production by luteal cells (Abayasekara and Wathes, 1999; Mattos et al., 2000).

\section{Parturition and Retained Placenta}

Parturition is a process that is accompanied by the massive release of prostaglandins. Alterations of fatty acids in the endometrium have been described in normal parturition, and manipulations of fatty acid content used experimentally to delay onset of parturition. Fatty acids of the omega-3 family have been shown to affect uterine activity during parturition in rats and sheep, and to delay the onset of parturition (Petit et al, 2002). Supplementing linolenic acid to a diet deficient in essential fatty acids resulted in an impairment of parturition rates (Abayasekara and Wathes, 1999, Petit et al, 2002). This 
also occurred when fish oil was given to rats as the major dietary essential fatty acid source, and an inhibition of uterine synthesis of $\mathrm{PGE}_{2}$ was detected (Thatcher et al., 2004). In pre-term pregnant sheep, intravenous infusion of a $20 \%$ omega-3 fatty acid emulsion resulted in a delay in the onset of induced labour and delivery compared with a control group infused with an emulsion of soybean oil containing 7\% omega-3 fatty acids (Petit et al, 2002). This has been attributed to the changed pattern of prostaglandins synthesis, which gives rise to an increase in the generation of 3-series prostaglandins. Since 3-series prostaglandins are less potent than the 2-series prostaglandins normally associated with parturition, the suggestion is that the biological activity of these 3 -series prostaglandins is insufficient to induce the vigorous myometrial contractions associated with normal labour (Abayasekara and Wathes, 1999; Mattos, et al., 2000).

Forages could also affect reproduction. Barnouin and Chassagne (1991) reported that cows fed grass silage had lower blood PG concentrations than those fed corn silage. Grass silage had greater concentration of linolenic acid and lower concentration of linoleic acid than corn silage. As a result, the incidence of retained placenta in cows fed grass silage was higher than in cows fed corn silage. As linolenic acid is an inhibitor of PG secretion, a high linolenic to linoleic acid ratio (grass silage) therefore could result in retained placenta. Kemp et al. (1998) reported that cows requiring more time to expulse their placenta also had lower PG metabolite blood concentrations at calving. However, in their experiment, the linolenic to linoleic acid ratio had no effect on delivery time of placenta probably because the difference in the linolenic to linoleic acid ratio between flaxseed and sunflower seed based diets was not large enough. This would suggest that fatty acid composition of forages and diets could have important effects on cow reproduction.

\section{Conclusions}

Polyunsaturated fatty acids such as $\alpha$-linoleic, linolenic, eicosapentaenoic and docosahexaenoic acids can affect reproductive function and fertility. Linoleic acid is found mainly in oilseeds, whereas $\alpha$-linolenic is found predominantly in forages and in some oilseeds (flaxseed); eicosapentaenoic and docosahexaenoic acids are high in fish oils. Feeding omega 3 fatty acids has increased CL diameter and progesterone concentration in dairy cows. Dairy cows fed diets high in eicosapentaenoic and docosahexaenoic acids (supplementation with menhaden fish meal) or $\alpha$-linolenic acid (supplementation with flaxseed) during early pregnancy had reduced $\mathrm{PGF}_{2 \alpha}$ production and increased pregnancy rates. Feeding diets high in $\alpha$-linolenic acid during the dry period may increase the incidence of placental retention. Dietary supplementation of select polyunsaturated fatty acids during the postpartum period has the potential to improve fertility in dairy cows, but more research is essential.

\section{References}

Abayasekara DRE, Wathes DC. 1999. Effects of altering dietary fatty acid composition on prostaglandin synthesis and fertility. Prost. Leukot. Essent. Fatty Acids, 61: 275-287
Ambrose J, Kastelic P. 2003. Dietary fatty acids and dairy cow fertility. Advances in Dairy Technology, 15: 35-47.

Ashes JR, Sieber BD, Gulati SK, Cuthbertson AZ, Scott TW. 1992. Incorporation of n-3 fatty acids of fish oil into tissue and serum lipids of ruminants. Lipids, 27: 629-631.

Barnouin J, Chassagne M. 1991. An aetiological hypothesis for the nutrition-induced association between retained placenta and milk fever in the dairy cows. Ann. Rech. Vet., 22: 331-343.

Beam SW, Butler WR. 1997. Energy balance and ovarian follicle development prior to the first ovulation in dairy cows receiving three levels of dietary fat. Biol. Reprod., 56: 133-142.

Burke JM, Staples RC, Risco CA, De LaSota RL, Thatcher WW. 1997. Effect of ruminant grade Menhaden fish meal on reproductive and productive performance of lactating dairy cows. J. Dairy Sci., 80: 3386-3398.

Cerri RL, Juchem SO, Chebel RC, Rutigliano HM, Bruno RG, Galvão KN, Thatcher WW, Santos JE. 2009. Effect of fat source differing in fatty acid profile on metabolic parameters, fertilization, and embryo quality in high-producing dairy cows. J Dairy Sci., 92: 1520-1531.

Dipak B, Bhagwat SR, Pawar MM, Chauhan HD, Srivastava AK, Kulkarni RC, Makwana RB. 2013. Effect of dietary fat on reproduction in cattle. J. Anim. Feed. Sci. Tech. 57: 91-102.

Hawkins DE, Niswender KD, Oss GM, Moeller CL, Odde KG, Sawyer HR, Niswender GD. 1995. An increase in serum lipids increases luteal lipid content and alters the disappearance rate of progesterone in cows. J. Anim. Sci., 73: 541-545.

Juchem S, Cerri R, Villasenor M. 2010. Supplementation with calcium salts of linoleic and trans-octadecenoic acids improves fertility of lactating dairy cows. Reprod. Domest. Anim., 45: 5562.

Kemp B, Soede NM, Kankofer M, Bevers M, Taverne MAM, Wensing Th, Noordhuizen JPTM. 1998. Influence of linoleic/linolenic acid ratio in the diet of periparturient cattle on plasma concentrations of PGF $2 \alpha$ metabolite and placental expulsion rate. Theriogenology, 49:571-580.

Kuran M, Onal AG, Robinson JJ, Mackie K, Speake BK, McEvoy TG. 1999. A dietary supplement of calcium soaps of fatty acids enhances luteal function in sheep. Anim. Sci., 69: 355-393.

Lammoglia MA, Willard ST, Hallford DM, Randel RD. 1997. Effects of dietary fat on follicular development and circulating concentrations of lipids, insulin, progesterone, estradiol $17 \mathrm{~b}$, 13,14-dihydro-15-ketoprostaglandin F2, and growth hormone in estrous cyclic Brahman cows. J. Anim. Sci., 75: 1591-1600

Mattos R, Staples R, Thatcher W. 2000. Effects of dietary fatty acids on reproduction in ruminants. J. Reprod. Fert., 5: 38-45.

Otto JR, Freeman MJ, Malau-Aduli BS, Nichols PD, Lane PA, Malau-Aduli AEO. 2014. Reproduction and fertility parameters of dairy cows supplemented with omega-3 fatty acid-rich canola oil. Annual Res. Rev. Biol., 4: 1611-1636.

Petit HV, Dewhurst RJ, Proulx JG, Khalid M, Haresign W, Twagiramungu H. 2001. Milk production, milk composition, and reproductive function of dairy cows fed different fats. Can. J. Anim. Sci., 81: 263-271

Petit HV, Dewhurst RJ, Scollan ND, Proulx JG, Khalid M, Haresign W, Twagiramungu H, Mann GE. 2002. Milk production and composition, ovarian function, and prostaglandin secretion of dairy cows fed omega-3 fats. J. Dairy Sci., 85: 889-899.

Rodney RM, Celi P, Scott W, Breinhild K, Lean IJ. 2015. Effects of dietary fat on fertility of dairy cattle: A meta-analysis and metaregression. J. Dairy. Sci., 98: 5601-5620.

Thatcher WW, Bilby T, Staples CR, MacLaren L, Santos J. 2004. Effects of polyunsaturated fatty acids on reproductive processes in dairy cattle. In: Proceedings of the Southwest Nutrition \& Management Conference, February 26-27, pp. 1-13.

Thatcher WW, Binelli M, Burke J, Staples CR., Ambrose JD, Coelho S. 1997. Antiluteolytic signals between the conceptus and endometrium. Theriogenology, 47: 131-140.

Thatcher WW, de la Sota RL, Schmitt EJP, Diaz TC, Badinga L, Simmen FA, Staples CR, Drost M. 1996. Control and management of Ovarian Follicles in cattle to optimize fertility. Reprod. Fertil. Dev., 8: 203-217. 